Genetic and biochemical analysis of glucosinolate breakdown: The effects of indole-3carbinol on plant physiology and development

Chamovitz, A.D. Tel Aviv University

Jander, G. Boyce Thompson Institute NY

Project award year: 2012

Three year research project 


\section{ABSTRACT}

\section{Genetic and biochemical analysis of glucosinolate breakdown: The effects of indole-3-carbinol on plant physiology and development}

Glucosinolates are a class of defense-related secondary metabolites found in all crucifers, including important oilseed and vegetable crops in the Brassica genus and the well-studied model plant Arabidopsis thaliana. Upon tissue damage, such as that provided by insect feeding, glucosinolates are subjected to catalysis and spontaneous degradation to form a variety of breakdown products. These breakdown products typically have a deterrent effect on generalist herbivores. Glucosinolate breakdown products also contribute to the anti-carcinogenic effects of eating cabbage, broccoli and related cruciferous vegetables. Indole-3-carbinol, a breakdown product of indol-3-ylmethylglucosinolate, forms conjugates with several other plant metabolites. Although some indole-3-carbinol conjugates have known functions in defense against herbivores and pathogens, most play as yet unidentified roles in plant metabolism, and possibly also plant development. At the outset, our proposal had three main hypotheses: (1) There is a specific detoxification pathway for indole-3-carbinol; (2) Metabolites derived from indole-3-carbinol are phloem-mobile and serve as signaling molecules; and (3) Indole-3-carbinol affects plant cell cycle and cell-differentiation pathways. The experiments were designed to enable us to elucidate how indole-3-carbinol and related metabolites affect plants and their interactions with herbivorous insects. We discovered that indole-3carbinol rapidly and reversibly inhibits root elongation in a dose-dependent manner, and that this inhibition is accompanied by a loss of auxin activity in the root meristem. A direct interaction between indole-3-carbinol and the auxin perception machinery was suggested, as application of indole-3-carbinol rescued auxin-induced root phenotypes. In vitro and yeast-based protein interaction studies showed that indole-3-carbinol perturbs the auxin-dependent interaction of TIR1 with Aux/IAA proteins, supporting the notion that indole-3-carbinol acts as an auxin antagonist. Furthermore, transcript profiling experiments revealed the influence of indole-3-carbinol on auxin signaling in root tips, and indole-3-carbinol also affected auxin transporters. Brief treatment with indole-3-carbinol led to a reduction in the amount of PIN1 and to mislocalization of PIN2. The results indicate that chemicals induced by herbivory, such as indole-3-carbinol, function not only to repel herbivores, but also as signaling molecules that directly compete with auxin to fine tune plant growth and development, which implies transport of indole-3carbinol that we are as yet unsuccessful in detecting. Our results indicate that plant defensive metabolites also have secondary functions in regulating aspects of plant metabolism, thereby providing diversity in defense-related plant signaling pathways. Such diversity of of signaling by defensive metabolites would be beneficial for the plant, as herbivores and pathogens would be less likely to mount effective countermeasures. We propose that growth arrest can be mediated directly by the herbivory-induced chemicals, in our case, indole-3-carbinol. Thus, glucosinolate breakdown to I3C following herbivory would have two outcomes: (1) Indole-3-carbinaol would inhibit the herbivore, while (2) at the same time inducing growth arrest within the plant. Thus, our results indicate that I3C is a defensive phytohormone that modulates auxin signaling, leading to growth arrest. 
Summary Sheet

PubType IS only Joint US only

Reviewed 1 10 


\section{Details of cooperation}

This program could never have been accomplished without the close cooperation of both laboratories. The Jander lab provided the expertise in analysis of glucosinolate breakdown products, and overall expertise and familiarity with the subject matter, while the Chamovitz lab provided the original hypothesis, and experience in the cellular, yeast and in vitro analyses that were carried out. Ella Katz, a PhD student in the Chamovitz lab, spent several weeks in the Jander lab learning the intricacies of I3C measurement. Prof. Chamovitz also spent a week in Ithaca, going over results, and writing the manuscript with Prof. Jander. In addition, Katz, Chamovitz Jander, and Jander's postdoc, Melkamu Woldemariam, were in close contact by email and by Skype conference calls. It is clear that without these interactions, this project would not have succeeded.

\section{Publications}

Katz, E., Nisani, S., Yadav, B.S., Woldemariam, M.G., Shai, B., Obolski, U., Ehrlich, M., Shani, E., Jander, G. and Chamovitz, D.A. (2015) The glucosinolate breakdown product indole-3-carbinol acts as an auxin antagonist in roots of Arabidopsis thaliana. Plant J, 82, 547-555.

- Selected as featured article of the issue.

Katz, E., Nisani, S., Sela M., Behar H., and Chamovitz, D.A. (2015) The effect of indole-3-carbinol on PIN1 and PIN2 in Arabidopsis roots. Plant Signaling \& Behavior. DOI: 


\section{Achievements}

\section{Genetic and biochemical analysis of glucosinolate breakdown: The effects of indole-3-carbinol on plant physiology and development}

The main scientific finding of our research was highlighted as the cover article in The Plant Journal (Katz et al., 2015b)There we showed that the glucosinolate (GS) breakdown product indole-3-carbinol (I3C) inhibits root elongation, probably by acting as an auxin antagonist. We first observed that $\mathrm{I} 3 \mathrm{C}$ inhibits roots growth in a dose-dependent manner, and that this effect is reversible. Since inhibition of root elongation is a typical auxin exposure phenotype, we hypothesized that I3C impacts auxin signaling in the root, and indeed found that $\mathrm{I} 3 \mathrm{C}$ treatment rapidly and reversibly reduced auxin signaling in the root tip.

Our results indicated that $\mathrm{I} 3 \mathrm{C}$ reduces auxin signaling by acting as an auxin antagonist on the TIR1 receptor. Surprisingly, this mode of action was apparently specific for I3C and is not common to all I3M-GS breakdown products. Although indole-3acetonitrile (IAN) also inhibited root elongation, its influence on auxin signaling was different from that of I3C. Thus, I3M-GS breakdown products likely influence plant development at multiple levels.

Taken together with our second publication (Katz et al., 2015a), our results clearly demonstrate that $\mathrm{I} 3 \mathrm{C}$ influences plant growth by directly modulating auxin signaling. The implication for agriculture is that chemicals induced by herbivory, such as $\mathrm{I} 3 \mathrm{C}$, function not only to repel the herbivore, but also as signaling molecules within the plant. Thus, our results suggest that $\mathrm{I} 3 \mathrm{C}$ is a defensive phytohormone that modulates auxin signaling, leading to growth arrest.

Salicylic acid and jasmonic acid, the two best-studied plant defense signaling molecules, are likely to have originally evolved as small molecule metabolites that provided direct defense against herbivores and pathogens (Jander and Clay, 2011). 
Jasmonic acid not only induces numerous plant defense responses, but also influences primary metabolism, for instance reducing the synthesis of sugars and amino acids (Adio et al., 2011). Our results imply that other plant defensive metabolites might also have secondary functions in regulating aspects of plant metabolism, which provide diversity in defense-related plant signaling pathways. Such diversity of defensive metabolites in defense-related plant signaling pathways would be beneficial for the plant as herbivores and pathogens would be less likely to mount effective countermeasures.

The idea that herbivory also affects plant development is not new. Many studies have shown that herbivory induces plant growth arrest (Adler and Wink, 2001; Poveda et al., 2003). Such arrest has most often been attributed to changes in resource allocation, e.g. the growth differentiation balance hypothesis (Gershenzon, 1994; Massad et al., 2012). We propose that the growth arrest can also be signaled directly by the induced chemicals, in our case I3C. Thus glucosinolate breakdown to I3C following herbivory would have two outcomes: (1) I3C would inhibit the herbivore, while (2) at the same time inducing growth arrest within the plant.

Interestingly, a recent article reported that volatile indoles released from soil bacteria modulate auxin signaling in roots (Bailly et al., 2014). Thus the idea that indolecontaining metabolites negatively influence auxin signaling appears to be an emerging paradigm.

Our hypothesis that other plant defensive metabolites might also have secondary functions in regulating aspects of plant metabolism formed the basis for our recently funded BARD proposal which employs, in addition to Arabidopsis, also maize and barley as model systems. Thus the results of the BARD program have allowed us to progress from basic research with Arabidopsis to research on crop plants. 


\section{References}

Adio AM, Casteel CL, De Vos M, Kim JH, Joshi V, Li B, Juery C, Daron J, Kliebenstein DJ, Jander G (2011) Biosynthesis and defensive function of $N$-deltaacetylornithine, a jasmonate-induced Arabidopsis metabolite. Plant Cell 23: 33033318

Adler LS, Wink M (2001) Transfer of quinolizidine alkaloids from hosts to hemiparasites in two Castilleja-Lupinus associations: analysis of floral and vegetative tissues. Biochemical systematics and ecology 29: 551-561

Bailly A, Groenhagen U, Schulz S, Geisler M, Eberl L, Weisskopf L (2014) The interkingdom volatile signal indole promotes root development by interfering with auxin signalling. Plant $\mathbf{J}$

Gershenzon J (1994) Metabolic costs of terpenoid accumulation in higher plants. Journal of chemical ecology 20: 1281-1328

Jander G, Clay N (2011) New synthesis--plant defense signaling: new opportunities for studying chemical diversity. J Chem Ecol 37: 429

Katz E, Nisani S, Sela M, Behar H, Chamovitz DA (2015a) The effect of indole-3carbinol on PIN1 and PIN2 in Arabidopsis roots. Plant Signal Behav 10: e1062200

Katz E, Nisani S, Yadav BS, Woldemariam MG, Shai B, Obolski U, Ehrlich M, Shani E, Jander G, Chamovitz DA (2015b) The glucosinolate breakdown product indole-3-carbinol acts as an auxin antagonist in roots of Arabidopsis thaliana. Plant J 82: $547-555$

Massad TJ, Dyer LA, Vega CG (2012) Costs of defense and a test of the carbon-nutrient balance and growth-differentiation balance hypotheses for two co-occurring classes of plant defense. Plos One 7: e47554

Poveda K, Steffan-Dewenter I, Scheu S, Tscharntke T (2003) Effects of below- and above-ground herbivores on plant growth, flower visitation and seed set. Oecologia 135: 601-605 
Publications for Project IS-4505-12R

Status Type Authors Title

Journal

Volume:

Pages

Year

Country

Katz, E., Nisani, S.,

Yadav, B.S.

Woldemariam, M.G. The glucosinolate breakdown

Published Reviewed Shai, B., Obolski, U., product indole-3-carbinol acts as

Ehrlich, M., Shani, an auxin antagonist in roots of

Plant J

82 :

Arabidopsis thaliana.

$\begin{array}{ll}82: & 2015 \quad \text { Joint }\end{array}$

E., Jander, G. and

Chamovitz, D.A.

Katz, E., Nisani, S., The effect of indole-3-carbinol

Plant Signaling and 10 :

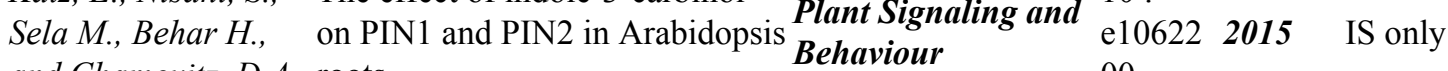

Published Reviewed
and Chamovitz, D.A. roots. 00 


\title{
The glucosinolate breakdown product indole-3-carbinol acts as an auxin antagonist in roots of Arabidopsis thaliana
}

\author{
Ella Katz ${ }^{1}$, Sophia Nisani ${ }^{1}$, Brijesh S. Yadav ${ }^{1}$, Melkamu G. Woldemariam ${ }^{2}$, Ben Shai ${ }^{3}$, Uri Obolski ${ }^{1}$, Marcelo Ehrlich ${ }^{3}$, \\ Eilon Shani ${ }^{1}$, Georg Jander ${ }^{2}$ and Daniel A. Chamovitz ${ }^{1, *}$ \\ ${ }^{1}$ Molecular Biology and Ecology of Plants, Tel Aviv University, Ramat Aviv 69978, Israel, \\ ${ }^{2}$ Boyce Thompson Institute, Ithaca, NY 14853, USA, and \\ ${ }^{3}$ Cell Research and Immunology, Tel Aviv University, Ramat Aviv 69978, Israel
}

Received 10 October 2014; revised 26 February 2015; accepted 4 March 2015; published online11 March 2015.

*For correspondence (e-mail dannyc@tauex.tau.ac.il).

\begin{abstract}
SUMMARY
The glucosinolate breakdown product indole-3-carbinol functions in cruciferous vegetables as a protective agent against foraging insects. While the toxic and deterrent effects of glucosinolate breakdown on herbivores and pathogens have been studied extensively, the secondary responses that are induced in the plant by indole-3-carbinol remain relatively uninvestigated. Here we examined the hypothesis that indole-3-carbinol plays a role in influencing plant growth and development by manipulating auxin signaling. We show that indole-3-carbinol rapidly and reversibly inhibits root elongation in a dose-dependent manner, and that this inhibition is accompanied by a loss of auxin activity in the root meristem. A direct interaction between indole-3-carbinol and the auxin perception machinery was suggested, as application of indole-3-carbinol rescues auxin-induced root phenotypes. In vitro and yeast-based protein interaction studies showed that indole-3-carbinol perturbs the auxin-dependent interaction of Transport Inhibitor Response (TIR1) with auxin/3-indoleacetic acid (Aux/IAAs) proteins, further supporting the possibility that indole-3-carbinol acts as an auxin antagonist. The results indicate that chemicals whose production is induced by herbivory, such as indole-3-carbinol, function not only to repel herbivores, but also as signaling molecules that directly compete with auxin to fine tune plant growth and development.
\end{abstract}

Keywords: indole-3-carbinol, auxin, herbivory, Arabidopsis thaliana, glucosinolate.

\section{INTRODUCTION}

The phytochemical indole-3-carbinol (I3C) functions in cruciferous vegetables as a protective agent against foraging insects (Kim and Jander, 2007), and is used in humans as a dietary supplement with anti-carcinogenic properties (Aggarwal and Ichikawa, 2005). I3C is a breakdown product of glucosinolates, which are a diverse group of small molecules produced in the Cruciferae family, including Brassica vegetables, such as broccoli and cauliflower, and also Arabidopsis thaliana (Fahey et al., 2001). Tissue damage from herbivores or physical means initiates hydrolysis of glucosinolates by endogenous plant $\beta$-thioglucosidases (commonly called myrosinases). Further catalysis and spontaneous degradation result in the formation of a wide variety of chemicals, including I3C (McDanell et al., 1988; Halkier and Gershenzon, 2006). These glucosinolate breakdown products, in addition to their bioactive properties, cause the characteristic sharp taste of cruciferous vegetables (Bones and Rossiter, 1996; Keck and Finley, 2004; Kim and Milner, 2005). I3C is formed from the breakdown of indole-3-ymethylglucosinolate (I3M-GS), one of the most widely distributed glucosinolates (Agerbirk et al., 2009). I3C, in turn, reacts with itself and a variety of other plant metabolites to form conjugates. In addition to their toxic effects on herbivorous insects, glucosinolate breakdown products may also signal further plant defense responses (Clay et al., 2009); therefore, it is possible that I3M-GS breakdown triggers downstream responses in Arabidopsis and other crucifers. While specific roles for these $\mathrm{I} 3 \mathrm{C}$ conjugates are slowly being revealed, most have as yet unknown functions in plant metabolism (Kim et al., 2008).

Glucosinolate breakdown products have also been implicated in human health, with $\mathrm{I} 3 \mathrm{C}$ in particular being studied as a therapeutic dietary supplement for women recovering from breast cancer (Bradlow, 2008). In human cells, I3C has been implicated in the inhibition of cell-cycle progression, induction of apoptosis, and inhibition of tumor invasion and metastasis (Meng et al., 2000a,b; Firestone and Bjeldanes, 2003; Sarkar and Li, 2004; Fan et al., 2006). The 
mechanism by which I3C mediates these processes is unclear, although direct involvement with a variety of signaling pathways has been suggested (Li et al., 2003).

While the toxic and deterrent effects of glucosinolate breakdown on herbivores and pathogens have been studied extensively, the secondary responses that are induced by $I 3 C$ in plants remain relatively uninvestigated. Here we use the Arabidopsis root as a model system to elucidate pathways influenced by I3C. We show that I3C inhibits root elongation and competes with auxin perception in vitro and in vivo, suggesting that $\mathrm{I} 3 \mathrm{C}$ acts as an auxin antagonist that has the potential to inhibit growth under biotic stress conditions.

\section{RESULTS}

\section{Exogenous I3C is taken up by Arabidopsis seedlings}

To confirm that $\mathrm{I} 3 \mathrm{C}$ is taken up by Arabidopsis, seedlings

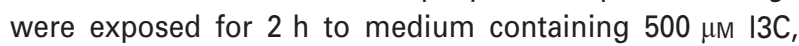
and analyzed by HPLC. The I3C-treated seedlings contained approximately $10 \mathrm{nmol} \mathrm{g}^{-1} \mathrm{I3C}$, whereas untreated controls had no detectable $13 \mathrm{C}$ (Figure 1). Similar accumulation of $13 C$ was observed in cyp79B2 cyp79B3 seedlings, which do not form indole glucosinolates (Hull et al., 2000), and tgg 1 tgg 2 seedlings, which do not degrade indole glucosinolates to I3C (Barth and Jander, 2006), an indication that the observed $\mathrm{I} 3 \mathrm{C}$ accumulation is not the product of endogenous glucosinolate degradation.

\section{Exogenous $\mathrm{I} 3 \mathrm{C}$ treatment inhibits root elongation}

To examine the effect of exogenous $13 \mathrm{C}$ on the growth of Arabidopsis roots, we first analyzed primary root lengths of Arabidopsis seedlings germinated on increasing concentrations of I3C. I3C inhibited root elongation in a dose-dependent

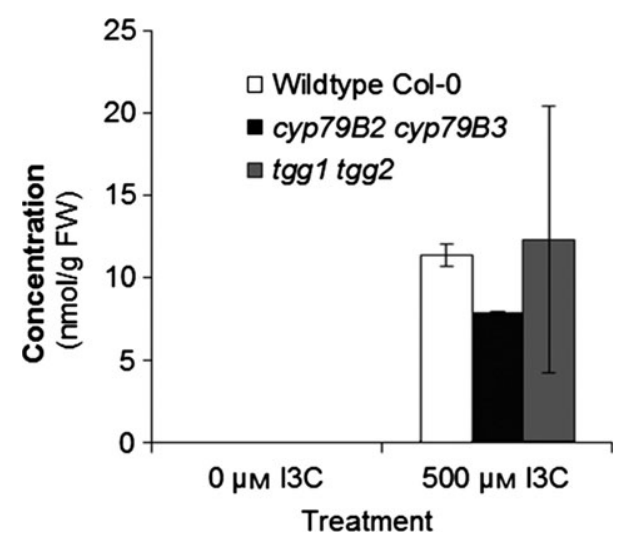

Figure 1. Uptake of $I 3 C$ by Arabidopsis seedlings. Two-week-old Arabidopsis seedlings germinated in liquid MS medium were exposed to $500 \mu \mathrm{M} \mathrm{I3C}$ for $2 \mathrm{~h}$ or left untreated. I3C was not detected in untreated seedlings. Values are means \pm SE of three replicates, each comprising 50 seedlings. The $13 \mathrm{C}$ levels in seedlings treated with $I 3 C$ were higher than the levels in control seedlings for all three genotypes $(P<0.05$, ANOva followed by Tukey's HSD test). FW, fresh weight. manner (Figure 2a). Extrapolation of growth rates revealed $50 \%$ inhibition of root growth $\left(\mathrm{IC}_{50}\right)$ at $125 \mu \mathrm{m} \mathrm{I3C}$, with $95 \%$ inhibition $\left(\mathrm{IC}_{95}\right)$ at approximately $400 \mu \mathrm{m}$ (Figure $2 \mathrm{~b}$ ). Given that Arabidopsis seedlings contain $1.4 \mu \mathrm{g} \mathrm{I3M-GS} \mathrm{per} \mathrm{gram}$ root dry weight (Petersen et al., 2002), corresponding to approximately $140 \mu \mathrm{m}$ concentration, and the majority of this is converted to $\mathrm{I} 3 \mathrm{C}$ after tissue damage, the local concentrations of $\mathrm{I} 3 \mathrm{C}$ may be within the range of the $\mathrm{IC}_{50}$ for exogenous $13 \mathrm{C}$.

To study the kinetics of root growth inhibition after application of I3C, we grew seedlings on MS medium for 4 days, transferred them to solid medium with or without $400 \mu \mathrm{M} \mathrm{I3C}$, and used time-lapse photography to monitor root elongation over $24 \mathrm{~h}$ (Movie S1). A decrease in the root elongation rate was immediately evident upon transfer to $\mathrm{I} 3 \mathrm{C}$ medium. As shown in Figure 2(c), 60 min after transfer, the rate of root elongation of seedlings transferred to medium containing $\mathrm{I} 3 \mathrm{C}$ was significantly lower than the rate of root elongation of seedlings transferred to medium without I3C (Student's $t$ test, $P<0.01$ ).

To determine whether this growth arrest is reversible, seedlings that had been germinated and grown on $\mathrm{I} 3 \mathrm{C}$ for 8 days were transferred to fresh MS plates. Whereas the root elongation rate on $400 \mu \mathrm{M} I 3 \mathrm{C}$ was negligible compared with the rate on MS, the roots began to elongate upon transfer to MS medium at a rate approaching that of seedlings that had never been exposed to I3C (Figure S1). This indicates that the effect of $I 3 C$ on root growth is reversible.

\section{Other indole glucosinolate breakdown products influence root elongation}

After tissue damage, I3M-GS breakdown proceeds in two directions, leading either to the formation of $I 3 C$ and its derivates, or indole-3-acetonitrile (IAN) (Figure S2a) (Agerbirk et al., 2009). We thus examined the effect of additional indole glucosinolate breakdown products $\left(3,3^{\prime}\right.$ diindolylmethane, indole-3-carboxaldehyde and methylindole-3-carboxalate) on the growth of Arabidopsis roots. All chemicals tested inhibited root elongation (Figure S2b), thus we continued our analysis using I3C and IAN to represent the two breakdown pathways.

\section{Exogenous $\mathrm{I} 3 \mathrm{C}$ treatment inhibits auxin signaling}

Inhibition of root growth is a typical phenotype of plants exposed to exogenous auxin, or plants with reduced endogenous auxin (List, 1969; Overvoorde et al., 2010). Given the similar structures of I3C, IAN and 3-indoleacetic acid (IAA), with the difference being that $I 3 C$ has a terminal hydroxyl group and IAN has a terminal cyanide, whereas IAA has a terminal carboxylic acid, we tested the hypothesis that in addition to IAA, I3C and IAN also induce auxin signaling in the root apical meristem. For this purpose, we used seedlings expressing DR5::N7-VENUS. In these 
Figure 2. $13 \mathrm{C}$ treatment inhibits root elongation.

(a) Phenotypes of 14-day-old plants grown on increasing concentrations of $\mathrm{I3C}$.

(b) Percentage inhibition of root elongation of seedlings grown on various concentrations of $\mathrm{I3C}$. Inhibition was extrapolated based on regression fitting. (c) Kinetics of root elongation inhibition by I3C Seedlings were grown on MS medium for 4 days, and transferred to medium with or without $400 \mu \mathrm{m}$ 13C. Root lengths for seven seedlings were measured every $20 \mathrm{~min}$ for each treatment. Asterisks indicate a statistically significant difference compared with I3C-containing medium $\left({ }^{*} P<0.01\right.$, Student's $t$ test). Values are means \pm standard errors. (a)

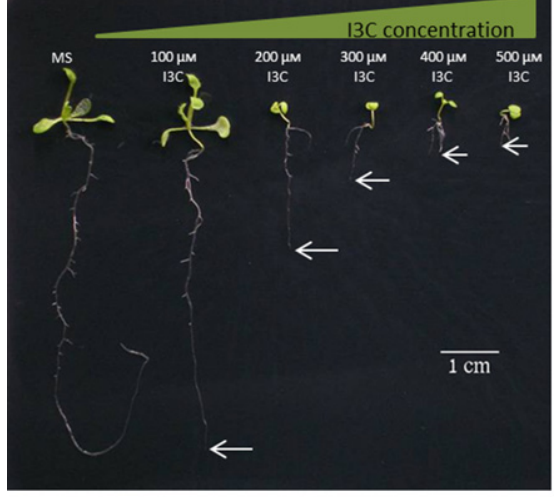

(b)

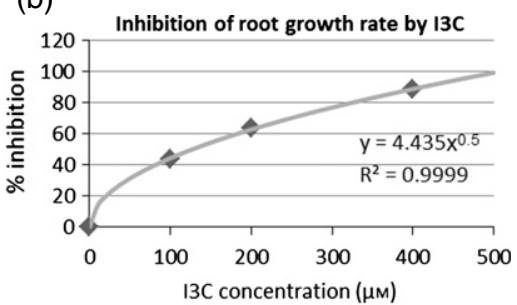

(c) Elongation of roots grown on different media

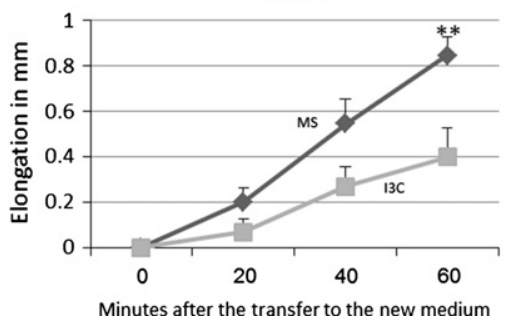

plants, the VENUS marker is a reporter for auxin responses (Ulmasov et al., 1997; Heisler et al., 2005). Seedlings were grown on MS medium for 6 days, treated with or without $200 \mu \mathrm{M}$ I3C or $90 \mu \mathrm{m}$ IAN for $6 \mathrm{~h}$, and the YFP fluorescence was monitored. While IAN indeed increased the activity of the auxin reporter in epidermal and cortex cells, exogenous treatment with $\mathrm{I} 3 \mathrm{C}$ reduced the activity of the reporter gene, contrary to our hypothesis (Figure 3a).

To determine whether the effect of I3C on the DR5::N7VENUS signal is a direct response to changes in auxin perception and to elucidate its dynamics, we used plants expressing the VENUS protein fused to auxin interaction domain II of Aux/IAA (DII-VENUS) (Brunoud et al., 2012). In these plants, the VENUS signal is sensitive to exogenous and endogenous auxin in a dose-dependent manner, without disrupting the activity of the auxin response machinery (Vernoux et al., 2011; Brunoud et al., 2012). Five-day-old DII-VENUS plants were treated with IAA, or both IAA and I3C, and the YFP fluorescence was monitored after $30 \mathrm{~min}$ using confocal microscopy. Thirty minutes following IAA treatment, low fluorescence of YFP was measured in the seedlings, indicating a high auxin signal. When the seedlings were treated with both $I A A$ and $I 3 C$, an increase in YFP fluorescence was measured, suggesting that $I 3 C$ inhibited IAA perception within 30 min (Figure $3 b$ ).

To determine whether the effect of $I 3 C$ on auxin signaling is reversible, we measured the activity of the DR5::GUS reporter gene in seedlings that had been germinated on $400 \mu \mathrm{M} \mathrm{I3C}$ and were transferred to fresh MS plates after 4 days. As shown in Figure 3(c), seedlings grown on medium containing $\mathrm{I} 3 \mathrm{C}$ show a low level of GUS activity at the root apical meristem, but 1 day after transfer to fresh medium without $13 \mathrm{C}$, the GUS activity at the root apical meristem was high, indicating that the effect of exogenous I3C on auxin distribution is reversible.

\section{$\mathrm{I3C}$ acts as an auxin antagonist}

As $13 \mathrm{C}$ treatment led to a rapid reduction in auxin activity in the root apical meristem, and as the structure of $\mathrm{I} 3 \mathrm{C}$ and auxin are very similar (Figure 4a), we hypothesized that I3C may act as an auxin antagonist. We further hypothesized that $\mathrm{I} 3 \mathrm{C}$ interacts specifically with the auxin binding site of the Transport Inhibitor Response (TIR1) receptor (Gray et al., 2001; Dharmasiri et al., 2005), thus perturbing the interaction of TIR1/Auxin signaling F-Box (AFBs) with auxin/3-indoleacetic acid (Aux/IAAs) (Ken-ichiro Hayashi et al., 2012).

To evaluate whether $13 \mathrm{C}$ is an auxin antagonist, we first modeled the potential interaction of I3C with TIR1, based on the crystal structure of auxin binding with TIR1 (Tan et al., 2007). Our model predicts that while both $I 3 C$ and IAN are able to associate with the auxin receptor site of TIR1, this putative interaction is with different regions of TIR1 (Figure 4b). Like IAA, I3C interacts with TIR1 chain B, while IAN putatively interacts with chain $C$ (Figure $4 b$ ). Other $\mathrm{I} 3 \mathrm{C}$ derivates also potentially interact with chain $\mathrm{B}$ (Figure S3). While I3C and IAN both inhibit root elongation, only $\mathrm{ISC}$ appears to negatively affect auxin signaling, potentially by competing with IAA with respect to binding to TIR1. As I3C and auxin differ in the residue attached to the 3rd carbon of their indole ring, I3C interaction with the auxin binding site of TIR1 may potentially perturb the docking of the Aux/IAA proteins, and thus directly inhibit the auxin response.

To test the hypothesis that $\mathrm{I} C \mathrm{C}$ is an auxin antagonist, we analyzed the effect of $13 C$ on three typical auxin responses: inhibition of root elongation, initiation of root hair formation, and promotion of lateral root formation. We monitored the root lengths of seedlings grown for 6 days on medium containing various concentrations of 

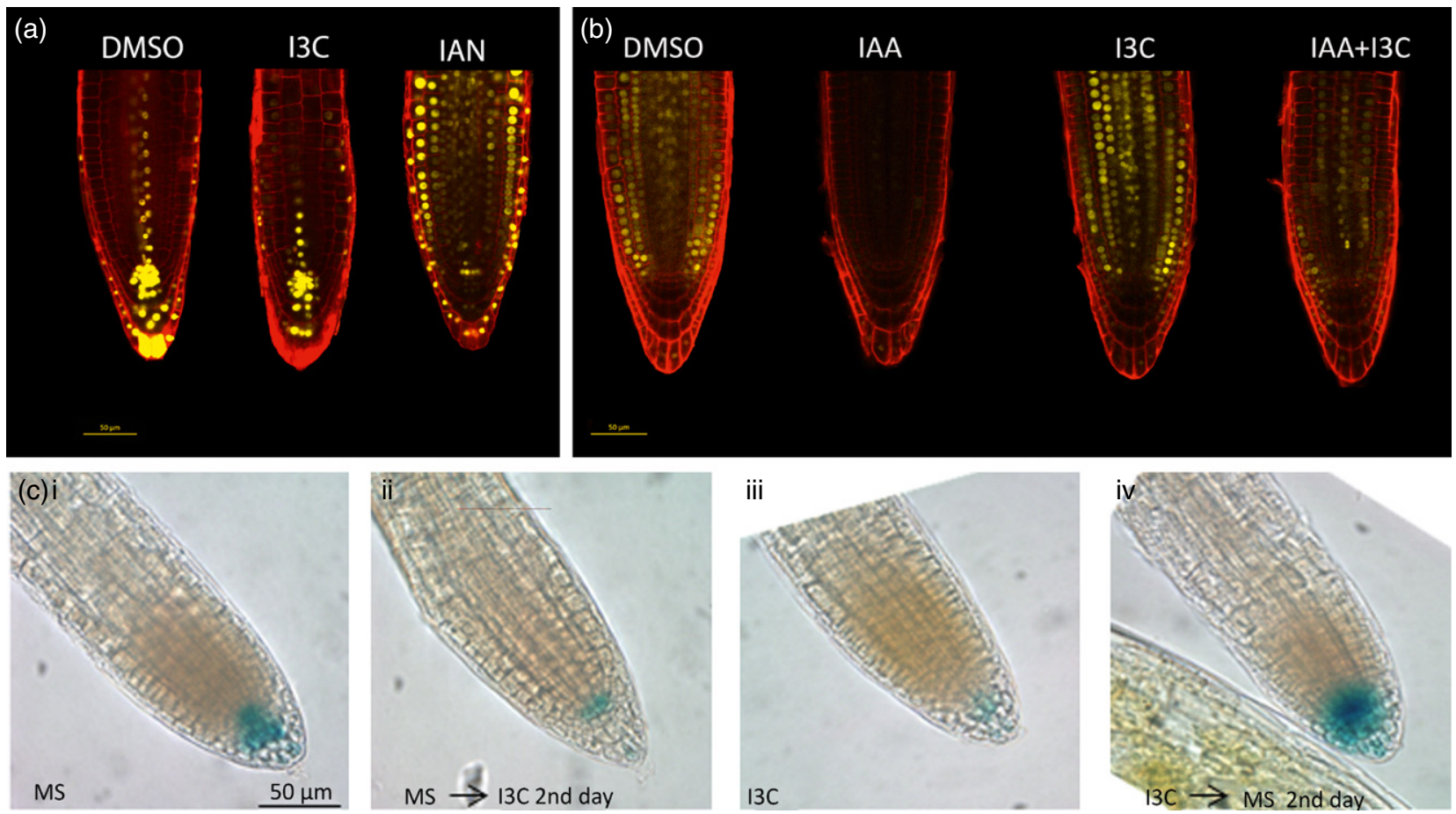

Figure 3. $13 \mathrm{C}$ reversibly inhibits auxin signaling in the root tip.

(a) Seedlings expressing DR5::N7-VENUS were grown on MS medium for 6 days, treated with $200 \mu \mathrm{m}$ I3C or $90 \mu \mathrm{M}$ IAN for $6 \mathrm{~h}$, and imaged using confocal microscopy. Cell walls were stained using propidium iodide. Quantification of the relative integrated density of the VENUS fluorescence showed a significant decrease in the VENUS signal after I3C treatment (55\% of the signal for the control plants), and a significant increase in the VENUS signal after IAN treatment (323\% of the signal for the control plants). For each treatment, $5-10$ seedlings were used $(P<0.001$; Student's $t$ test). Bar is $50 \mu \mathrm{m}$.

(b) I3C affects auxin signaling within $30 \mathrm{~min}$. Five-day-old DII-VENUS seedlings grown on MS medium were treated for 30 min with $0.05 \mu \mathrm{M}$ IAA, $300 \mu \mathrm{M} I 3 \mathrm{C}$, or both, and imaged using confocal microscopy. Cell walls were stained using propidium iodide. Quantification of the relative integrated density of the VENUS fluorescence showed a significant decrease in the VENUS signal after IAA treatment (21\% of the signal for the control plants), and a significant increase (173\%) in the VENUS signal after treatment with both IAA and I3C compared to IAA-treated plants, suggesting that I3C inhibited the effect of IAA on auxin signaling within $30 \mathrm{~min}$. For each treatment, $4-7$ seedlings were used $(P<0.01$; Student's $t$ test). Bar is $50 \mu \mathrm{m}$.

(c) The effect of I3C on auxin signaling is reversible. DR5::GUS seedlings were grown on MS medium or on medium containing $400 \mu \mathrm{M}$ I3C for 4 days, then transferred to the other medium for 2 days, the roots were photographed on the second day following transfer.

auxin, $13 \mathrm{C}$, or both. As expected, roots of plants grown in the presence of auxin or $13 \mathrm{C}$ were significantly shorter than roots of plants grown on MS (Figure 5a). However, seedlings grown in the presence of both $\mathrm{I} 3 \mathrm{C}$ and auxin exhibited roots that were significantly longer than those grown solely on auxin (but shorter than those grown on MS), suggesting that $\mathrm{I} 3 \mathrm{C}$ partially antagonizes the effect of excess auxin. Similar results were obtained when assessing the number of root hairs and lateral roots on seedlings grown for 4 days on medium containing various concentrations of auxin, I3C, or both. As expected, the number of both root hairs and lateral roots was higher in plants treated with IAA (Figure $5 \mathrm{~b}, \mathrm{c}$ ). Exposure to $\mathrm{I} 3 \mathrm{C}$ led to a reduction in the number of root hairs and lateral roots. The roots of seedlings grown in the presence of both $\mathrm{I} 3 \mathrm{C}$ and auxin exhibited a reduction in the number of root hairs and lateral roots compared to those grown on IAA alone, further indicating that $\mathrm{I} C \mathrm{C}$ partially antagonizes the effect of excess auxin.

If $\mathrm{I} 3 \mathrm{C}$ acts as an auxin antagonist, it is expected to directly manipulate the auxin perception machinery.
Villalobos et al. (2012) previously showed that auxin promotes interaction between the auxin receptors TIR1/AFBs and Aux/IAA (IAA) family proteins in yeast two-hybrid assays. We utilized this system and found that $13 \mathrm{C}$ perturbs the interaction between TIR1 and IAA7 that is facilitated by auxin, but IAN does not (Figure 6a). Yeast expressing TIR1-LexA and Gal4-IAA7 fusion proteins were grown on medium containing auxin, $I 3 C$ or $I A N$, or both $I 3 C$ and auxin, or IAN and auxin. Expression of the $\beta$-galactosidase reporter was monitored 4 days after spotting. As a negative control, we used LexA yeast expressing TIR1 and an empty plasmid instead of IAA7, and as a positive control, we used LexA yeast expressing Pto and AvrPto, which are known to interact (Bogdanove and Martin, 2000). As shown in Figure 6(a), the interaction between TIR1 and IAA7 was facilitated when the yeast grew on medium containing auxin, consistent with previous studies (Villalobos et al., 2012). This interaction was diminished when we added I3C to the growth medium in addition to auxin, but not when IAN was added to the auxin. The reduction in interaction was apparent at $50 \mu \mathrm{m} \mathrm{I3C}$, and almost complete at $150 \mu \mathrm{m}$ 
(a)<smiles>O=C(O)Cc1c[nH]c2ccccc12</smiles><smiles>OCc1c[nH]c2ccccc12</smiles>

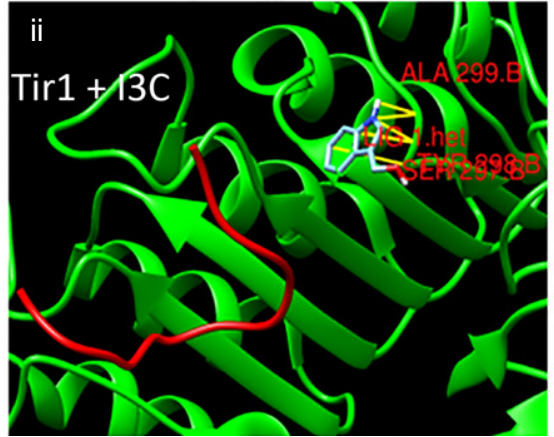<smiles>N#CCc1c[nH]c2ccccc12</smiles>

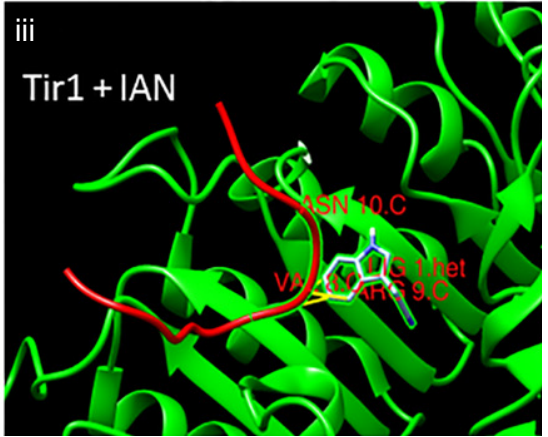

Figure 4. Modeling of I3C/IAN binding to TIR1.

(a) Structure of auxin (IAA), I3C and IAN.

(b) Predicted interaction of I3C (i) or IAN (iii) with TIR1 based on auxin binding (i). Blue represents I3C (ii), IAN (iii) or IAA (i), and yellow lines represent hydrogen bonds between TIR1 and IAA/I3C/IAN. IAA and I3C bind to chain B of TIR1 (green helix) with binding energies of $-4.5 \mathrm{kcal}^{-1} \mathrm{l}^{-1}$ for TIR1/IAA and $-4.1 \mathrm{kcal} \mathrm{mol}^{-1}$ for TIR1/I3C. IAN binds to chain C of TIR1 (red chain), with a binding energy of $-4.5 \mathrm{kcal} \mathrm{mol}^{-1}$.

Figure 5. I3C rescues IAA-driven root phenotypes. (a) Seedlings were grown on MS medium containing $0.2 \mu \mathrm{M}$ IAA, $300 \mu \mathrm{M}$ I3C, or both. At 6 days, seedlings were photographed $\left(a^{\prime}\right)$ and root length was measured

(b) Seedlings were grown on MS medium for 4 days, and then transferred to medium containing $0.2 \mu \mathrm{M}$ IAA, $300 \mu \mathrm{m} \mathrm{I3C}$, or both. At 8 days, seedlings were photographed $\left(b^{\prime}\right)$ and the number of root hairs was counted.

(c) Seedlings were grown on MS medium for 4 days, and then transferred to medium containing $0.5 \mu \mathrm{m}$ IAA, $200 \mu \mathrm{M}$ I3C, or both. At 8 days, seedlings were photographed $\left(c^{\prime}\right)$ and the number of lateral roots was counted. Multiple comparisons between treatments using ANOVA followed by a Tukey's HSD test revealed that all treatments were statistically significantly different $(P<0.01)$, except for $I A A+\mid 3 C$ in comparison with $13 C$, for all measures. Values are means \pm standard errors. For each treatment, 7-45 seedlings were used.
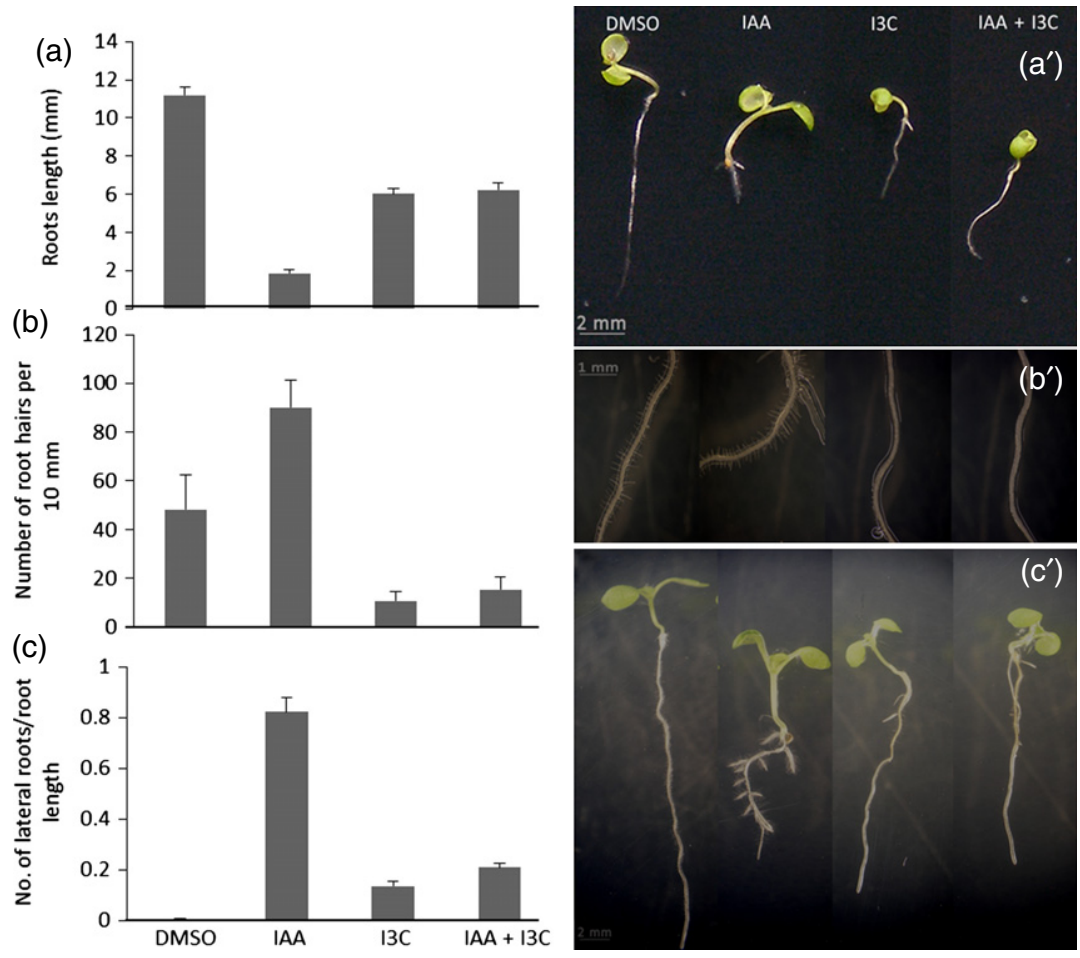

I3C. While a slight reduction in yeast growth was noticed in the presence of $13 \mathrm{C}$, this did not inhibit the interaction of Pto and AvrPto (positive control).

To further confirm the yeast two-hybrid assay results, we performed an in vitro pull-down assay using in vitro translated TIR1-Myc and recombinant GST-IAA3 protein purified from Escherichia coli (Parry et al., 2009). The proteins were pulled down using GST beads in the presence or absence of $100 \mu \mathrm{m}$ IAA or $100 \mu \mathrm{m}$ IAA plus $10 \mathrm{~mm}$ I3C, separated by SDS-PAGE, and the interaction between TIR1 and IAA3 was detected using an anti-c-Myc antibody. As expected, the in vitro interaction between TIR1 and IAA3 was apparent only when auxin was present in the reaction mixture (Figure $6 \mathrm{~b}$, lane III) as indicated by the high TIR1/IAA3 ratio. 
(a) $\mathrm{i}$
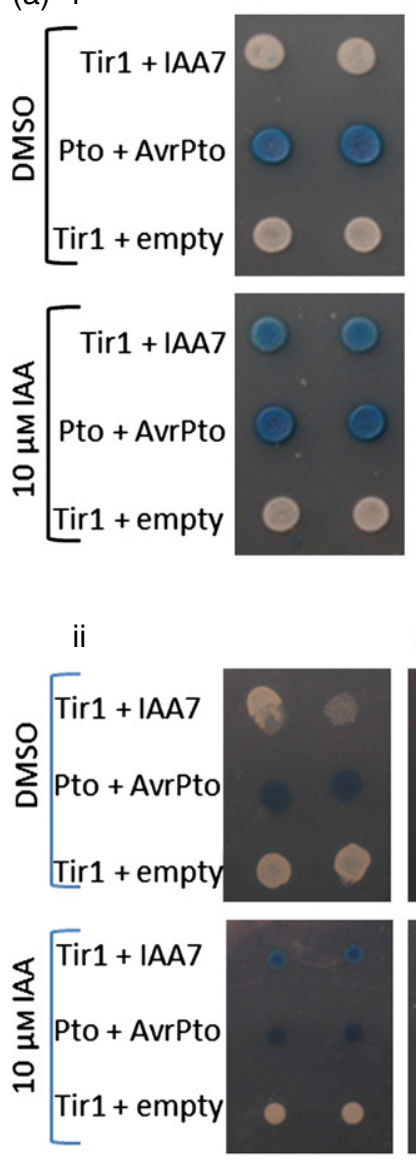

$50 \mu \mathrm{M} \mathrm{I3C}$
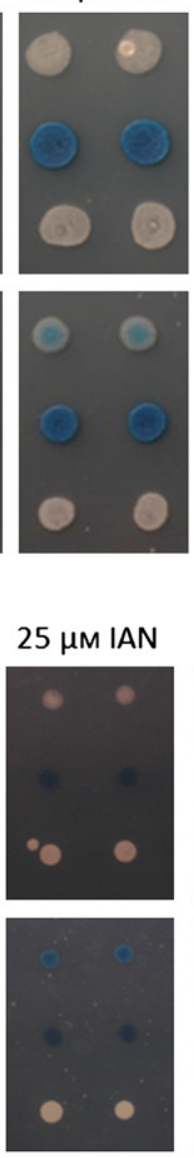

$100 \mu \mathrm{M} I 3 \mathrm{C}$
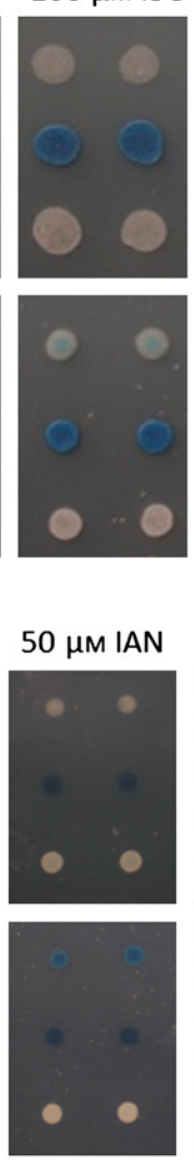

$150 \mu \mathrm{M} \mathrm{I3C}$

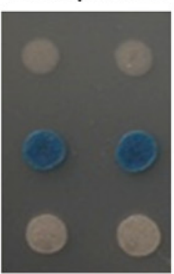

(b)
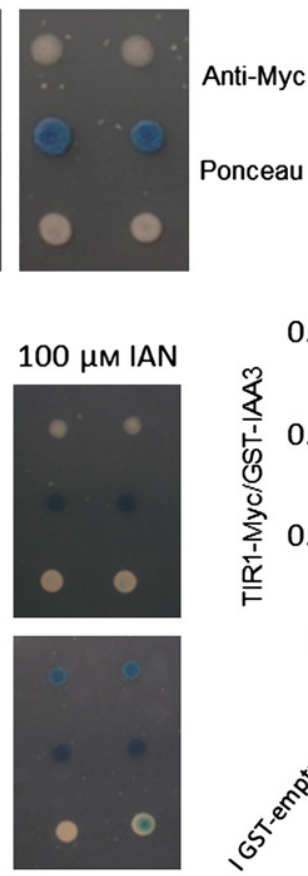
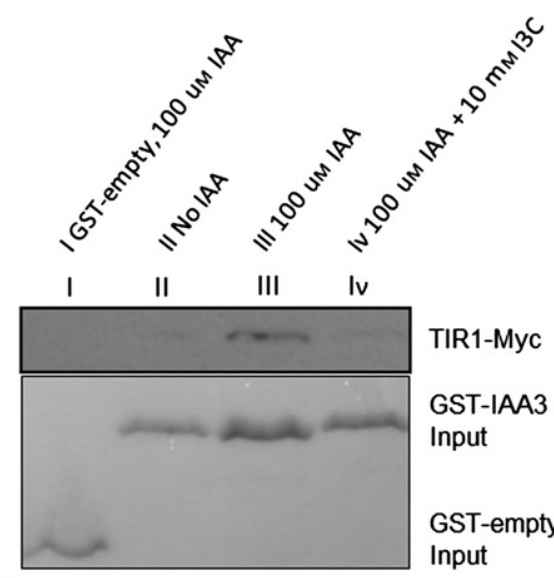

TIR1-Myc

GST-IAA3

Input

GST-empty Input

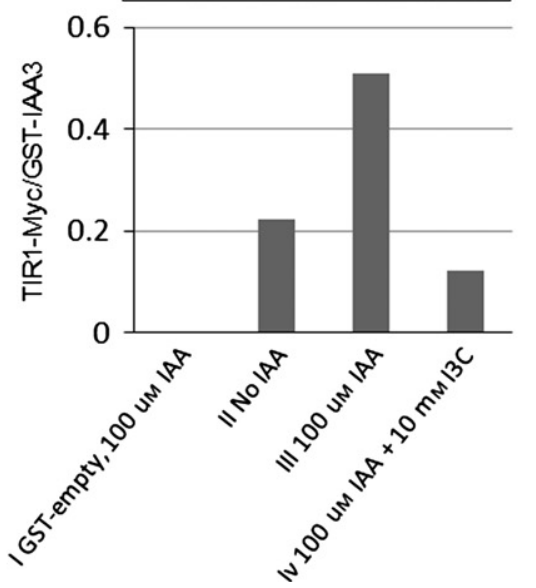

Figure 6. $I 3 \mathrm{C}$ perturbs auxin-dependent interaction of TIR1 and IAA proteins in yeast and in vitro.

(a) LexA yeast expressing TIR1 or Tir1 and IAA7 was grown on medium containing IAA, I3C or IAN, or both I3C and auxin (i), or IAN and auxin (ii). Expression of the $\beta$-galactosidase reporter expression was monitored 4 days after spotting.

(b) An in vitro pull-down assay of TIR1-Myc and GST-IAA3 was performed using recombinant GST-IAA3 and in vitro translated TIR1-Myc. The pull-down assays were incubated at $4^{\circ} \mathrm{C}$ for $1 \mathrm{~h}$ in the presence (lanes I and III) or absence (lane II) of $100 \mu \mathrm{m}$ auxin, or in the presence of $10 \mathrm{~mm}$ I3C and $100 \mu \mathrm{M}$ auxin (lane IV).

Addition of $\mathrm{I} 3 \mathrm{C}$ to the reaction mixture resulted in a reduction in the TIR1 and IAA3 ratio (Figure $6 \mathrm{~b}$, lane IV), indicating that $\mathrm{I} C \mathrm{C}$ inhibited the auxin-mediated interaction between TIR1 and IAA3. Taken together, the results of these experiments suggest that $\mathrm{I} 3 \mathrm{C}$ modulates auxin action in an antagonistic manner.

\section{DISCUSSION}

Here we show that the glucosinolate breakdown product indole-3-carbinol (I3C) inhibits root elongation, probably acting as an auxin antagonist. We first observed that $\mathrm{I} 3 \mathrm{C}$ inhibits roots growth in a dose-dependent manner, and that this effect is reversible. As inhibition of root elongation is a typical auxin exposure phenotype, we hypothesized that $\mathrm{I} 3 \mathrm{C}$ affects auxin signaling in the root, and indeed found that $\mathrm{I} 3 \mathrm{C}$ treatment rapidly and reversibly reduced auxin signaling in the root tip.

Our results indicate that $\mathrm{I} 3 \mathrm{C}$ reduces auxin signaling by acting as an auxin antagonist on the TIR1 receptor. Several lines of evidence support this conclusion. First, molecular modeling predicted that $\mathrm{I} 3 \mathrm{C}$ associates with the auxin binding site of the TIR1 auxin receptor. Second, at the molecular level, auxin reporter genes were down-regulated after I3C treatment. Third, at the physiological level, I3C partially rescued the effect of IAA on several root phenotypes. Fourth, at the level of protein-protein interactions, I3C directly perturbed the auxin-dependent interaction of TIR1 with IAA proteins both in yeast and in vitro.

This mode of action is apparently specific for $13 \mathrm{C}$ but not all I3M-GS breakdown products, as although IAN also inhibited root elongation, its influence on auxin signaling was different to that of I3C. Thus I3M-GS breakdown products probably influence plant development at multiple levels.

Taken together, the results presented here clearly demonstrate that $\mathrm{I} 3 \mathrm{C}$ influences plant growth by directly modulating auxin signaling. The implication is that chemicals whose production is induced by herbivory, such as I3C, function not only to repel the herbivore, but also as signal- 
ing molecules within the plant. Thus, our results suggest that $\mathrm{I} 3 \mathrm{C}$ is a defensive phytohormone that modulates auxin signaling, leading to growth arrest.

Salicylic acid and jasmonic acid, the two best-studied plant defense signaling molecules, are likely to have originally functioned as small molecule metabolites that provided direct defense against herbivores and pathogens (Jander and Clay, 2011). Jasmonic acid not only induces numerous plant defense responses, but also influences primary metabolism, for instance reducing the synthesis of sugars and amino acids (Adio et al., 2011). Our results suggest that other plant defensive metabolites may also have secondary functions in regulating aspects of plant metabolism, providing diversity in defense-related plant signaling pathways. Such diversity of defensive metabolites in defense-related plant signaling pathways is beneficial for the plant, as herbivores and pathogens are less likely to be able to mount effective counter-measures.

The idea that herbivory also affects plant development is not new. Many studies have shown that herbivory induces plant growth arrest (Adler and Wink, 2001; Poveda et al., 2003). Such arrest has most often been attributed to changes in resource allocation, e.g. the growth differentiation balance hypothesis (Gershenzon, 1994; Massad et al., 2012). We propose that the growth arrest may also be signaled directly by the induced chemicals, i.e. $\mathrm{I} 3 \mathrm{C}$ in this case. Thus glucosinolate breakdown to $\mathrm{I} 3 \mathrm{C}$ after herbivory has two outcomes, i.e. $13 \mathrm{C}$ repels the herbivore, while at the same time inducing growth arrest within the plant.

Although our studies used exogenously applied I3C, the concentrations are within the amounts of indole glucosinolates found endogenously in Arabidopsis seedlings (approximately $140 \mu \mathrm{m}$ ). Furthermore, as not all of the exogenous $\mathrm{I} 3 \mathrm{C}$ is taken up by the plant (Figure 1), the I3C concentration within the plant after treatment is lower than the exogenous concentrations used. Thus, given that we observed approximately $40 \%$ root growth inhibition at $100 \mu \mathrm{m} \mathrm{I3C}$, this concentration is potentially physiologically relevant and similar to what would be perceived locally by a plant that has an insect chewing on its roots. Accordingly, the relative concentrations of auxin and $I 3 C$ in the cell may well be within the range of those used here. Auxin gradients form within the root tip to drive growth and development. While it is not clear what the exact levels of auxin concentration are in different cell types and at the subcellular level, studies have estimated that the IAA activity in roots is within the physiological range (nanomolar to micromolar) (Petersson et al., 2009; Band and King, 2012; Bargmann et al., 2013), and is probably low following wounding (Cheong et al., 2002). Hence, the concentration of IAA after wounding may be approximately 100 times lower than the concentration of $\mathrm{I} 3 \mathrm{C}$ after wounding.

Finally, a recent study showed that volatile indoles released from soil bacteria modulate auxin signaling in roots (Bailly et al., 2014). Thus, the idea that indole-containing metabolites negatively influence auxin signaling appears to be an emerging paradigm.

\section{EXPERIMENTAL PROCEDURES}

\section{Plant materials and growth assays}

The Arabidopsis strains used in this work were all in the Columbia- 0 (Col-0) background. The transgenic and mutant lines have been described previously: DR5::GUS (Ulmasov et al., 1997), DR5::N7VENUS (Heisler et al., 2005), DII-VENUS (Brunoud et al., 2012), cyp79B2 cyp79B3 (Hull et al., 2000), and tgg1 tgg2 (Barth and Jander, 2006). Seeds were cultivated in Petri plates using medium containing $0.8 \%$ agar, half-strength Murashige and Skoog salts (MS), and $1 \%$ sucrose, $\mathrm{pH}$ 5.7. The Petri plates were placed in chambers at $22^{\circ} \mathrm{C}$ under light/dark conditions of $16 \mathrm{~h}$ white light at $75 \mu \mathrm{mol} \mathrm{m} \mathrm{sec}^{-1}$ and $8 \mathrm{~h}$ darkness, at $55 \%$ relative humidity. For root phenotype experiments, plates were placed vertically in the chambers.

\section{Preparation of indole metabolites}

Indole-3-carbinol (I3C), 3-indoleacetic acid (IAA/auxin), indole-3-acetonitrile (IAN), 3,3'-diindolylmethane, indole-3-carboxaldehyde and methyl-indole-3-carboxalate (Sigma, https://www.sigmaaldrich.com/) were dissolved in dimethylsulfoxide to produce $1 \mathrm{~m}$ solutions, and stored in the dark at $-20^{\circ} \mathrm{C}$.

\section{D imaging system}

Seedlings were grown for 4 days on MS medium. The seedlings were transferred to MS medium with or without $400 \mu \mathrm{M} \mathrm{I3C}$ and photographed every 20 min over $24 \mathrm{~h}$ using a $4 \mathrm{D}$ imaging system developed at the laboratory of Hillel Fromm (Department of Molecular Biology and Ecology of Plants, Tel Aviv University, Israel). Root length was measured using IMAGEJ software (http://imagej.nih.gov/ij/).

\section{GUS reporter assay}

DR5::GUS seedlings were grown on agar plates with or without $\mathrm{I3C}$, and stained using X-Gluc as described by Weigel and Glazebrook (2002). The roots were transferred to slides with drops of double-distilled water, and photographed using a Zeiss Axioplan2 microscope (www.zeiss.com) and CELL A software, (Olympus, www.olympus-global.com).

\section{Confocal microscopy}

Four- to six-day-old seedlings from marker strains were transferred to liquid MS containing $200 \mu \mathrm{M}$ I3C or dimethylsulfoxide. After treatment, seedlings were submerged in $0.005 \mathrm{mg} \mathrm{ml}^{-1}$ propidium iodide in double-distilled water, placed on microscope slides, and imaged using a Zeiss LSM780 confocal microscope with $\times 20 / N A$ 0.8 . The fluorescence emission was collected between 590 and $720 \mathrm{~nm}$ (band pass) for propidium iodide, and between 520 and $580 \mathrm{~nm}$ (band pass) for yellow fluorescent protein (YFP). YFP fluorescence was quantified using IMAGEJ software (http://imagej. nih.gov/ij/).

\section{Measurement of I3C levels by HPLC}

$13 \mathrm{C}$ was dissolved in $80 \%$ methanol to prepare a $1 \mu \mathrm{g} \mathrm{ml}^{-1}$ stock solution. A serial dilution was used to generate a standard curve for subsequent quantification of $13 \mathrm{C}$ in plant samples. Samples were separated using a Waters 2790 pump system coupled to a 
Waters 2996 photodiode array detector (Waters, http://www.waters. com/). We used a Kinetex column (Phenomenex, www.phenomenex. $\mathrm{com} / ; 5 \mu \mathrm{m}, 18 \mathrm{C}, 100 \AA, 150 \times 4.60 \mathrm{~mm}$ ) and a solvent system comprising water (solvent $A$ ) and acetonitrile (solvent $B, 90 \% \mathrm{v} / \mathrm{v}$ in water). The HPLC running conditions were: $0-5 \mathrm{~min}, 100 \% A_{\text {; }}$ 5-24 min, 90\% A; 24-29 min, 30\% A; 29-35 min, 0\% A; 35-40 min, $90 \% \mathrm{~A}$, with a flow rate of $1 \mathrm{ml} \mathrm{min}^{-1}$.

\section{Quantification of I3C uptake by seedlings}

Seeds of wild-type Col-0, tgg1 tgg2 and cyp79B2 cyp79B3 were surface-sterilized using $30 \%$ sodium hypochlorite containing $0.05 \% \mathrm{v} / \mathrm{v}$ Tween-20, followed by rinsing in $70 \%$ ethanol and five rinses with sterile water (Weigel and Glazebrook, 2002). Seeds were planted in liquid MS medium, and grown for 2 weeks under a $16 \mathrm{~h}$ light/ $8 \mathrm{~h}$ dark regime at $22^{\circ} \mathrm{C}$. Half of the 2-week-old seedlings were treated with $500 \mu \mathrm{M} \mathrm{I3C}$, and the rest were left as untreated controls. After $2 \mathrm{~h}$, the seedlings were rinsed three times with deionized water, collected in liquid nitrogen, weighed, and lyophilized to dryness. The dried samples were ground to a fine powder, homogenized in $0.8 \mathrm{ml}$ of $80 \%$ methanol, and heated for $15 \mathrm{~min}$ at $75^{\circ} \mathrm{C}$. After centrifugation for $5 \mathrm{~min}$ at $15000 \mathrm{~g}$, the supernatant was loaded onto a $250 \mu \mathrm{l}$ Sephadex A25 column (Pharmacia Fine Chemicals, www.pfizer.com/). Samples were eluted using $2 \times 250 \mu \mathrm{l}$ of $80 \%$ methanol and $2 \times 200 \mu \mathrm{l}$ water, the eluents were combined and dried under vacuum, and the residue was re-dissolved in $100 \mu \mathrm{l}$ of $80 \%$ methanol. After filtering by centrifugation through MultiScreen-HV filter plates (Millipore, www.emdmillipore.com/), $20 \mu \mathrm{l}$ of the solution was analyzed by HPLC as described above.

\section{Molecular modeling of I3C docking to TIR1}

AutoDock Vina (Trott and Olson, 2010) was used for molecular docking analysis of $\mathrm{I} C \mathrm{C}$ with the TIR1 protein from A. thaliana (PDB ID 2P10). The two-dimensional structure of the I3C substrate, taken from the National Center for Biotechnology Information PubChem server (www.ncbi.nlm.nih.gov/), was converted into $3 \mathrm{D}$ coordinates via the CORINA server (www. molecular-networks.com/online_demos/corina_demo). The Lamarckian genetic algorithm in AutoDock was used to perform the automated molecular dockings. Docking of I3C with TIR1 protein was performed in two steps. In the preliminary step, dockings were performed to identify the potential binding sites on the TIR1 protein, and in the second step, the whole surface of the protein was covered with large grid maps, created by AutoGrid. The $x, y$ and $z$ grid dimensions were set to $72 \AA$, with grid points separated by $0.375 \AA$.

\section{Yeast two-hybrid assays}

Yeast two-hybrid assays were performed as described previously (Prigge et al., 2010). The TIR1 bait vector pGILDA and the IAA7 prey vector pB42AD (Prigge et al., 2010) were co-transformed into Saccharomyces cerevisiae strain EGY48 as described previously (Gietz and Schiestl, 2007). The negative control comprised yeast expressing pGILDA containing TIR1 and an empty pB42AD vector. As a positive control, we used yeast expressing the Pto and AvrPto proteins (Bogdanove and Martin, 2000).

\section{In vitro pull down assays}

In vitro pull-down assays were performed as described by Parry et al. (2009). Briefly, a TIR1-Myc fusion protein was synthesized using the TNT T7 coupled wheatgerm extract system (Promega, www.promega.com/). GST-IAA3 protein was expressed in the E. coli BL21 DE3 strain and purified using glutathione agarose beads (Sigma) in lysis buffer (50 mm Tris, $100 \mathrm{~mm} \mathrm{NaCl,} \mathrm{10 \%}$ glycerol, $0.1 \%$ Tween-20, pH 7, and protease inhibitors, Roche, www.roche.com/). Then $25 \mu \mathrm{l}$ of extract were incubated with GSTIAA3 beads in $200 \mu$ l lysis buffer ( $\mathrm{pH}$ 5.7) in the presence or absence of $100 \mu \mathrm{m} I A A$ or $100 \mu \mathrm{m} I A A$ plus $10 \mathrm{~mm} \mathrm{I3C}$, at $4^{\circ} \mathrm{C}$ for $1 \mathrm{~h}$. Unbound proteins were washed twice for four $\mathrm{min}$, at $4^{\circ} \mathrm{C}$ on microchromatography columns (Bio-Rad, www.bio-rad.com/) using the same buffer. Proteins were eluted using elution buffer comprising $100 \mathrm{~mm}$ Tris and $15 \mathrm{mg} \mathrm{ml}^{-1}$ reduced glutathione (Sigma), $\mathrm{pH} 8$, separated by SDS-PAGE and detected using monoclonal anti-c-Myc (Provided by Eran Bacharach, Department of Cell research and Immunology, Tel Aviv University, Israel). To standardize the input, the membranes were stained using $0.1 \%$ Ponceau-S in $5 \%$ acetic acid solution, band intensities were quantified using IMAGEJ software (http:// imagej.nih.gov/ij/l, and the ratio between the TIR1 and IAA3 input bands was calculated.

\section{ACKNOWLEDGEMENTS}

This research was supported by a grant from the Binational Agricultural Research and Development Fund (IS-4505-12R) to D.A.C. and G.J. B.Y. was supported by a fellowship from the PBC (Planning and Budgeting Committee) Fellowship Program for Outstanding Post-Doctoral Researchers from India. We thank Mark Estelle (Section of Cell and Developmental Biology, University of California, San Diego) for the TIR1 and Aux/IAA constructs. We thank Manely Rabanim, Hila Behar, Mor Sela, Ora Hazak, Tal Sherman, Roye Nuriel, Guido Sessa (Department of Molecular Biology and Ecology of Plants, Tel Aviv University, Israel) and Efrat Elis (Department of Cell Research and Immunology, Tel Aviv University, Israel) for technical assistance or providing reagents.

\section{SUPPORTING INFORMATION}

Additional Supporting Information may be found in the online version of this article.

Figure S1. The effect of I3C on root inhibition is reversible.

Figure S2. I3M-GS breakdown products inhibit root elongation.

Figure S3. Modeling of binding of I3C derivatives to TIR1.

Movie S1. Kinetics of inhibition of root elongation by I3C.

\section{REFERENCES}

Adio, A.M., Casteel, C.L., De Vos, M., Kim, J.H., Joshi, V., Li, B., Juery, C., Daron, J., Kliebenstein, D.J. and Jander, G. (2011) Biosynthesis and defensive function of $\mathrm{N}$-delta-acetylornithine, a jasmonate-induced Arabidopsis metabolite. Plant Cell, 23, 3303-3318.

Adler, L.S. and Wink, M. (2001) Transfer of quinolizidine alkaloids from hosts to hemiparasites in two Castilleja-Lupinus associations: analysis of floral and vegetative tissues. Biochem. Syst. Ecol. 29, 551-561.

Agerbirk, N., De Vos, M., Kim, J.H. and Jander, G. (2009) Indole glucosinolate breakdown and its biological effects. Phytochem. Rev. 8, 101-120.

Aggarwal, B.B. and Ichikawa, H. (2005) Molecular targets and anticancer potential of indole-3-carbinol and its derivatives. Cell Cycle, 4, 1201-1215.

Bailly, A., Groenhagen, U., Schulz, S., Geisler, M., Eberl, L. and Weisskopf, L. (2014) The interkingdom volatile signal indole promotes root development by interfering with auxin signalling. Plant J. 80, 758-771.

Band, L.R. and King, J.R. (2012) Multiscale modelling of auxin transport in the plant-root elongation zone. J. Math. Biol. 65, 743-785.

Bargmann, B.O., Vanneste, S., Krouk, G. et al. (2013) A map of cell typespecific auxin responses. Mol. Syst. Biol. 9, 688.

Barth, C. and Jander, G. (2006) Arabidopsis myrosinases TGG1 and TGG2 have redundant function in glucosinolate breakdown and insect defense. Plant J. 46, 549-562.

Bogdanove, A.J. and Martin, G.B. (2000) AvrPto-dependent Pto-interacting proteins and AvrPto-interacting proteins in tomato. Proc. Natl Acad. Sci. USA, 97, 8836-8840. 
Bones, A.M. and Rossiter, J.T. (1996) The myrosinase-glucosinolate system, its organisation and biochemistry. Physiol. Plant. 97, 194-208.

Bradlow, H.L. (2008) Review. Indole-3-carbinol as a chemoprotective agent in breast and prostate cancer. In Vivo, 22, 441-445.

Brunoud, G., Wells, D.M., Oliva, M. et al. (2012) A novel sensor to map auxin response and distribution at high spatio-temporal resolution. Nature, 482, 103-106.

Cheong, Y.H., Chang, H.S., Gupta, R., Wang, X., Zhu, T. and Luan, S. (2002) Transcriptional profiling reveals novel interactions between wounding, pathogen, abiotic stress, and hormonal responses in Arabidopsis. Plant Physiol. 129, 661-677.

Clay, N.K., Adio, A.M., Denoux, C., Jander, G. and Ausubel, F.M. (2009) Glucosinolate metabolites required for Arabidopsis innate immune response. Science, 323, 95-101.

Dharmasiri, N., Dharmasiri, S. and Estelle, M. (2005) The F-box protein TIR1 is an auxin receptor. Nature, $435,441-445$.

Fahey, J.W., Zalcmann, A.T. and Talalay, P. (2001) The chemical diversity and distribution of glucosinolates and isothiocyanates among plants. Phytochemistry, 56, 5-51.

Fan, S., Meng, Q., Auborn, K., Carter, T. and Rosen, E.M. (2006) BRCA1 and BRCA2 as molecular targets for phytochemicals indole-3-carbinol and genistein in breast and prostate cancer cells. Br. J. Cancer, 94, 407-426.

Firestone, G.L. and Bjeldanes, L.F. (2003) Indole-3-carbinol and 3-3'-diindolylmethane antiproliferative signaling pathways control cell-cycle gene transcription in human breast cancer cells by regulating promoterSp1 transcription factor interactions. J. Nutr. 133, 2448S-2455S.

Gershenzon, J. (1994) Metabolic costs of terpenoid accumulation in higher plants. J. Chem. Ecol. 20, 1281-1328.

Gietz, R.D. and Schiestl, R.H. (2007) Large-scale high-efficiency yeast transformation using the LiAc/SS carrier DNA/PEG method. Nat. Protoc. 2, 38-41.

Gray, W.M., Kepinski, S., Rouse, D., Leyser, O. and Estelle, M. (2001) Auxin regulates SCF(TIR1)-dependent degradation of AUX/IAA proteins. Nature, 414, 271-276.

Halkier, B.A. and Gershenzon, J. (2006) Biology and biochemistry of glucosinolates. Annu. Rev. Plant Biol. 57, 303-333.

Heisler, M.G., Ohno, C., Das, P., Sieber, P., Reddy, G.V., Long, J.A. and Meyerowitz, E.M. (2005) Patterns of auxin transport and gene expression during primordium development revealed by live imaging of the Arabidopsis inflorescence meristem. Curr. Biol. 15, 1899-1911.

Hull, A.K., Vij, R. and Celenza, J.L. (2000) Arabidopsis cytochrome P450s that catalyze the first step of tryptophan-dependent indole-3-acetic acid biosynthesis. Proc. Natl Acad. Sci. USA, 97, 2379-2384.

Jander, G. and Clay, N. (2011) New synthesis-plant defense signaling: new opportunities for studying chemical diversity. J. Chem. Ecol. 37, 429.

Keck, A.S. and Finley, J.W. (2004) Cruciferous vegetables: cancer protective mechanisms of glucosinolate hydrolysis products and selenium. Integr. Cancer Ther. 3, 5-12.

Ken-ichiro Hayashi, J.N., Hirose, M., Kuboki, A., Shimada, Y., Kepinski, S. and Nozaki, H. (2012) Rational design of an auxin antagonist of the SCFTIR1 auxin receptor complex. ACS Chem. Biol. 7, 590-598.

Kim, J.H. and Jander, G. (2007) Myzus persicae (green peach aphid) feeding on Arabidopsis induces the formation of a deterrent indole glucosinolate. Plant J. 49, 1008-1019.

Kim, Y.S. and Milner, J.A. (2005) Targets for indole-3-carbinol in cancer prevention. J. Nutr. Biochem. 16, 65-73.

Kim, J.H., Lee, B.W., Schroeder, F.C. and Jander, G. (2008) Identification of indole glucosinolate breakdown products with antifeedant effects on $\mathrm{My}$ zus persicae (green peach aphid). Plant J. 54, 1015-1026.
Li, Y., Li, X. and Sarkar, F.H. (2003) Gene expression profiles of I3C- and DIM-treated PC3 human prostate cancer cells determined by cDNA microarray analysis. J. Nutr. 133, 1011-1019.

List, A. Jr (1969) Transient growth responses of the primary roots of Zea mays. Planta, 87, 1-19.

Massad, T.J., Dyer, L.A. and Vega, C.G. (2012) Costs of defense and a test of the carbon-nutrient balance and growth-differentiation balance hypotheses for two co-occurring classes of plant defense. PLoS One, 7 , e47554.

McDanell, R., McLean, A.E., Hanley, A.B., Heaney, R.K. and Fenwick, G.R. (1988) Chemical and biological properties of indole glucosinolates (glucobrassicins): a review. Food Chem. Toxicol. 26, 59-70.

Meng, Q., Goldberg, I.D., Rosen, E.M. and Fan, S. (2000a) Inhibitory effects of indole-3-carbinol on invasion and migration in human breast cancer cells. Breast Cancer Res. Treat. 63, 147-152.

Meng, Q., Qi, M., Chen, D.Z., Yuan, R., Goldberg, I.D., Rosen, E.M., Auborn, K. and Fan, S. (2000b) Suppression of breast cancer invasion and migration by indole-3-carbinol: associated with up-regulation of BRCA1 and Ecadherin/catenin complexes. J. Mol. Med. 78, 155-165.

Overvoorde, P., Fukaki, H. and Beeckman, T. (2010) Auxin control of root development. Cold Spring Harb. Perspect. Biol. 2, a001537.

Parry, G., Calderon-Villalobos, L.I., Prigge, M., Peret, B., Dharmasiri, S., Itoh, H., Lechner, E., Gray, W.M., Bennett, M. and Estelle, M. (2009) Complex regulation of the TIR1/AFB family of auxin receptors. Proc. Natl Acad. Sci. USA, 106, 22540-22545.

Petersen, B.L., Chen, S., Hansen, C.H., Olsen, C.E. and Halkier, B.A. (2002) Composition and content of glucosinolates in developing Arabidopsis thaliana. Planta, 214, 562-571.

Petersson, S.V., Johansson, A.I., Kowalczyk, M., Makoveychuk, A., Wang, J.Y., Moritz, T., Grebe, M., Benfey, P.N., Sandberg, G. and Ljung, K. (2009) An auxin gradient and maximum in the Arabidopsis root apex shown by high-resolution cell-specific analysis of IAA distribution and synthesis. Plant Cell, 21, 1659-1668.

Poveda, K., Steffan-Dewenter, I., Scheu, S. and Tscharntke, T. (2003) Effects of below- and above-ground herbivores on plant growth, flower visitation and seed set. Oecologia, 135, 601-605

Prigge, M.J., Lavy, M., Ashton, N.W. and Estelle, M. (2010) Physcomitrella patens auxin-resistant mutants affect conserved elements of an auxinsignaling pathway. Curr. Biol. 20, 1907-1912.

Sarkar, F.H. and Li, Y. (2004) Indole-3-carbinol and prostate cancer. J. Nutr. 134, 3493S-3498S.

Tan, X., Calderon-Villalobos, L.I., Sharon, M., Zheng, C., Robinson, C.V. Estelle, M. and Zheng, N. (2007) Mechanism of auxin perception by the TIR1 ubiquitin ligase. Nature, 446, 640-645.

Trott, O. and Olson, A.J. (2010) AutoDock Vina: improving the speed and accuracy of docking with a new scoring function, efficient optimization, and multithreading. J. Comput. Chem. 31, 455-461.

Ulmasov, T., Murfett, J., Hagen, G. and Guilfoyle, T.J. (1997) Aux/IAA proteins repress expression of reporter genes containing natural and highly active synthetic auxin response elements. Plant Cell, 9, 1963-1971.

Vernoux, T., Brunoud, G., Farcot, E. et al. (2011) The auxin signalling network translates dynamic input into robust patterning at the shoot apex. Mol. Syst. Biol. 7, 508.

Villalobos, C., Caballero, E., Sanz-Blasco, S. and Nunez, L. (2012) Study of neurotoxic intracellular calcium signalling triggered by amyloids. Methods Mol. Biol. 849, 289-302.

Weigel, D. and Glazebrook, J. (2002) Arabidopsis: A Laboratory Manual. Cold Sping Harbor, NY: Cold Spring Harbor Laboratory Press. 


\section{The effect of indole-3-carbinol on PIN1 and PIN2 in Arabidopsis roots}

\section{Ella Katz, Sophia Nisani, Mor Sela, Hila Behar \& Daniel A Chamovitz}

To cite this article: Ella Katz, Sophia Nisani, Mor Sela, Hila Behar \& Daniel A Chamovitz (2015) The effect of indole-3-carbinol on PIN1 and PIN2 in Arabidopsis roots, Plant Signaling \& Behavior, 10:9, e1062200, DOI: 10.1080/15592324.2015.1062200

To link to this article: http://dx.doi.org/10.1080/15592324.2015.1062200

曲 Accepted online: 07 Aug 2015.

Submit your article to this journal

Ш Article views: 29

Q View related articles $\sqsubset$

View Crossmark data $־$ 


\section{The effect of indole-3-carbinol on PIN1 and PIN2 in Arabidopsis roots}

Ella Katz, Sophia Nisani, Mor Sela, Hila Behar, and Daniel A Chamovitz*

Molecular Biology and Ecology of Plants; Tel Aviv University; Ramat Aviv, Israel

Keywords: Arabidopsis thaliana, auxin, glucosinolate, indole 3 carbinol

*Correspondence to: Daniel A Chamovitz; Email: dannyc@tauex.tau.ac.il

Submitted: 06/08/2015

Accepted: 06/10/2015

http://dx.doi.org/10.1080/15592324.2015.1062200

Addendum to: Katz, E., Nisani, S., Yadav, B.S Woldemariam, M.G., Shai, B., Obolski, U., Ehrlich M., Shani, E., Jander, G. and Chamovitz, D.A. (2015) The glucosinolate breakdown product indole-3-carbinol acts as an auxin antagonist in roots of Arabidopsis thaliana. Plant J, 82, 547-555.
$\mathrm{T}$ he phytochemical indole-3-carbinol is produced in Cruciferous plants upon tissue rapture and deters herbivores. We recently showed that indole-3carbinol modulates auxin signaling in root tips. Here we present transcript profiling experiments which further reveal the influence of indole-3-carbinol on auxin signaling in root tips, and also show that I3C affects auxin transporters. Brief treatment with indole-3-carbinol led to a reduction in the amount of PIN1 and to mislocalization of PIN2.

Indole-3-carbinol (I3C) is a phytochemical endogenously produced in the Cruciferae plant family. It is formed from the breakdown of indole-3-methylglucosinolate (I3M), which is derived from glucose and tryptophan. ${ }^{1}$ I3M is the predominant indole glucosinolate, and one of the most prominent glucosinolates detected in roots. The cleavage of I3M to I3C is catalyzed by myrosinase. ${ }^{2,3}$

In humans, a rich cruciferous vegetables diet has been associated with reduced chances of cancer, and I3C as a therapeutic treatment has potential for both prevention and treatment of a wide verity of cancers, such as leukemia, breast cancer and prostate cancer among others. ${ }^{4-8}$

In Arabidopsis thaliana I3C is synthesized upon tissue rapture and deters herbivores. The glucosinolates and the myrosinase are normally stored in separate compartments in the plant cells. In response to plant damage or insect attack $\mathrm{I} 3 \mathrm{M}$ and the myrosinase are mixed and I3C is synthesized. I3C protects the plant as it is toxic to herbivores, insects and pathogens.

While the toxic and deterrent effects of glucosinolate breakdown on herbivores and pathogens have been extensively studied, the secondary responses that are induced in the plant by I3C are only now starting to be revealed. Recently we have found that I3C effects plant growth and development by modulating auxin signaling in the root tips. ${ }^{10}$

In an attempt to reveal a bigger picture of the effect of I3C on auxin signaling in Arabidopsis roots, we carried out microarray experiments that revealed the extensive effect of I3C on the plant at the molecular level in general, and more specifically, on auxin responsive genes. We also used seedlings expressing auxin transporters reporter genes to understand if the effect of $\mathrm{I} 3 \mathrm{C}$ is local or wide spread in the root.

The auxin-dependent interaction between SCF ${ }^{\text {TIR1 }}$ with the Aux/IAA proteins and subsequent degradation of the Aux/IAA transcriptional repressors regulates the transcription of auxin-induced genes. ${ }^{11-14}$ As we previously showed that I3C inhibits the interaction of auxin with TIR $1,{ }^{10}$ we hypothesized that auxin-regulated genes would be misregulated following $\mathrm{I} 3 \mathrm{C}$ treatment. We carried out a transcript-profiling experiment on roots tips briefly exposed to I3C. Gene ontology analysis showed that auxin-regulated genes are preferentially misregulated (FDR = 7.00E-05) in roots one hour following I3C treatment. The basal expression of at least 32 genes (12.8\%) from a set of 250 auxin regulated genes is misregulated following I3C treatment (Fig. 1).

The distribution of auxin in the root is determined mainly by its transporters. The PIN family of active auxin transporters particularly have a major role in regulating auxin distribution, ${ }^{15}$ and indeed different PIN proteins have a cell-specific polar localization [reviewed in ${ }^{16}$ ].

To understand if the effect of I3C on auxin is unique to the root tips or more wide spread, we checked if auxin transport is also affected by I3C treatment. For this 
purpose we used seedlings expressing PIN1:GFP or PIN2:GFP. ${ }^{17,18}$ Seedlings were grown on MS medium for 5 to 6 days, treated with $200 \mu \mathrm{M} \mathrm{I3C}$ for 30 minutes, and GFP fluorescence was monitored by confocal microscopy.

The PIN1 transporter directs auxin to the root tips to create the auxin maxima. Thus under normal conditions PIN1 is localized at the basal side of the cells of the vascular bundle and can also be found in the epidermal and cortical cells that surround the quiescent center $^{19}$ (Fig. 2A). Following the short I3C treatment, we detected a reduced amount of PIN1 protein in the epidermis and cortex (Fig. 2A). Quantification of the relative integrated density of the GFP fluorescence in these cells showed a significant decrease in the GFP signal following the I3C treatment (50\% of the signal of the control plants, $\mathrm{P}<0.01$; Student's t test).

The PIN2 transporter is localized at the basal side of the cortical cells and at the apical side of the epidermal cells ${ }^{19}$ (Fig. 2B). Following the short I3C

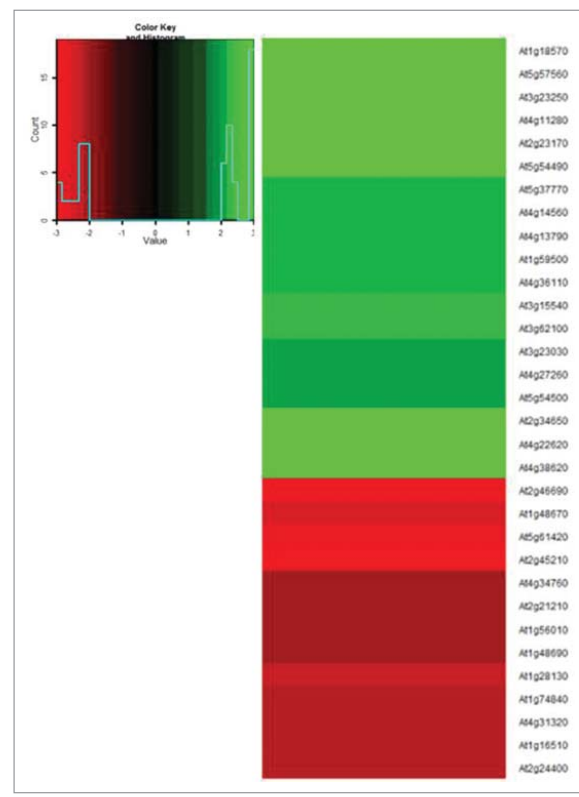

Figure 1. $\mathrm{I} C \mathrm{C}$ treatment leads to misregulation of auxin responsive genes. Heat map of the expression of known auxin-responsive genes following treatment with $500 \mu \mathrm{M} I 3 C$ for one hour. RNA was extracted from root tips of 10day-old seedlings and hybridized to Affymetrix ATH1 chips. A 2 fold cutoff was used. The list of auxin-responsive genes was extracted according to gene ontology in Agrigo [22].

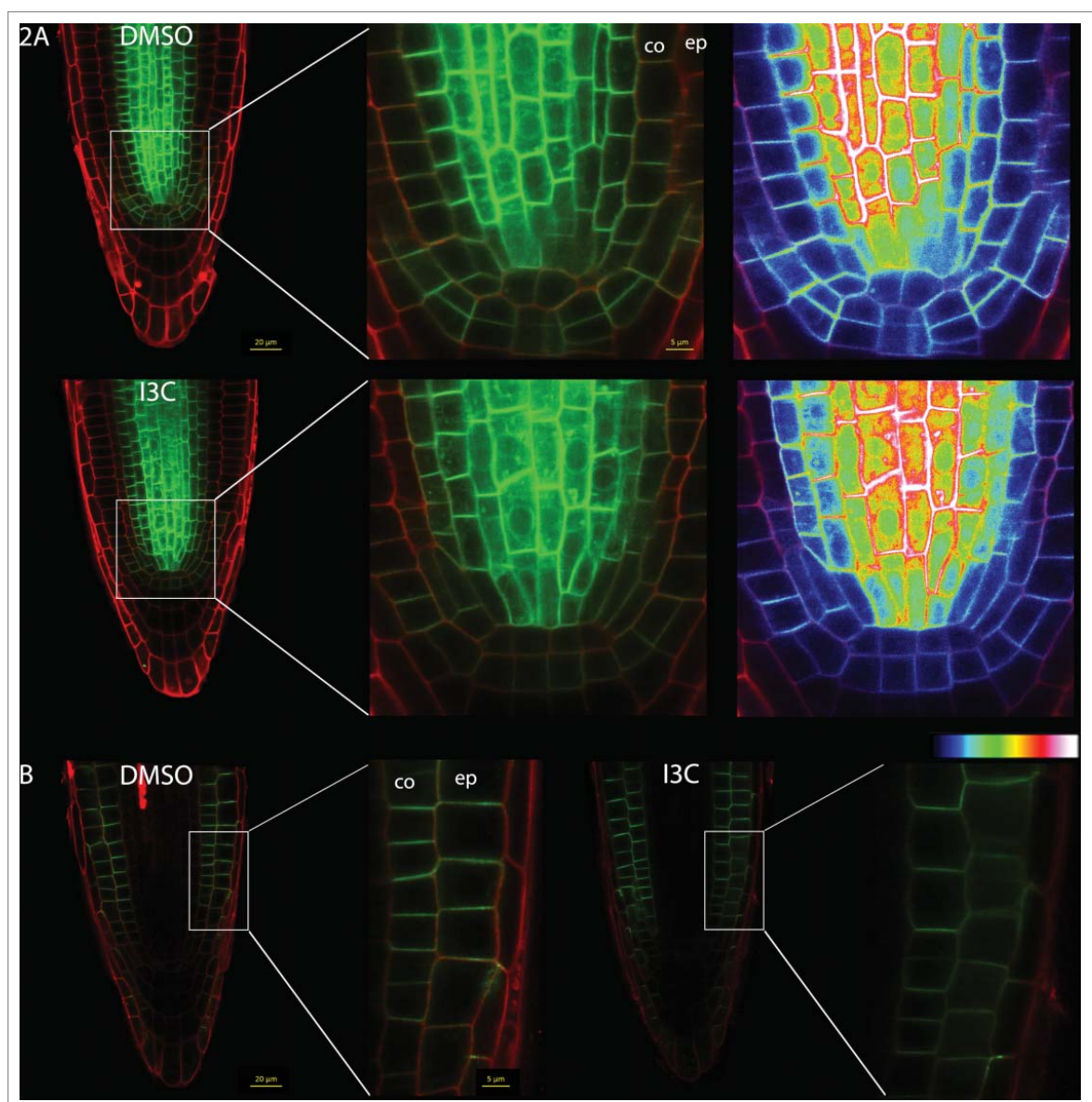

Figure 2. $\mathrm{I} 3 \mathrm{C}$ treatment affects auxin transporters. (A) Seedlings expressing PIN1:GFP were grown on MS medium for 5 days, treated with $200 \mu \mathrm{M}$ of I3C or with DMSO for 30 minutes, and imaged using confocal microscopy (Zeiss LSM780, with a 40x water objective). Heat-maps represent GFP density. GFP fluorescence was quantified using ImageJ software. (B) Seedlings expressing PIN2:GFP were grown on MS medium for 6 days, treated with $200 \mu \mathrm{M}$ of I3C or with DMSO for 30 minutes, and imaged using confocal microscopy (Zeiss LSM780, with a 40x water objective). Cell walls were stained using $0.005 \mathrm{mg} / \mathrm{ml}$ propidium iodide. co $=$ cortex ep $=$ epidermis.

treatment, we found that even though the amount of the PIN2 protein was not significantly changed following the I3C treatment, its localization was altered by the treatment. I3C treatment caused the PIN2 proteins to be more diffuse in the cells and less oriented to the cell membranes (Fig. 2B).

Based on the Sachs canalization hypothesis, ${ }^{20}$ it is plausible that the effect of I3C on the PIN proteins is not direct. According to this hypothesis, auxin signaling can affect its own transport by regulating its transporters. Indeed a change in auxin concentration in the root affects the polarization of PIN1 and PIN2. ${ }^{21}$ Since we have recently shown that $\mathrm{I} 3 \mathrm{C}$ modulates auxin signaling, ${ }^{10}$ this change might cause the mislocalization of PIN2 and the decrease in the amount of PIN1.

\section{Disclosure of Potential Conflicts of Interest}

No potential conflicts of interest were disclosed.

\section{Acknowledgments}

We thank the following for technical assistance: Dr. Eilon Shani, Iris Tal, and Dr. Daria Bloch.

\section{Funding}

This research was supported by a grant from the Binational Agricultural Research 
and Development Fund (BARD, IS4505-12R) to DAC. We thank Dr. Sigal Rencus-Lazar for critical reading.

\section{References}

1. Fahey JW, Zalcmann AT, Talalay P. The chemical diversity and distribution of glucosinolates and isothiocyanates among plants. Phytochemistry 2001 56:5-51; PMID:11198818; http://dx.doi.org/10.1016/S00319422(00)00316-2

2. Agerbirk N, De Vos M, Kim JH, Jander G. Indole glucosinolate breakdown and its biological effects. Phytochem Rev 2009; 8:101-20; http://dx.doi.org/10.1007/ s11101-008-9098-0

3. Halkier BA, Gershenzon J. Biology and biochemistry of glucosinolates. Annu Rev Plant Biol 2006; 57:303-33, PMID:16669764; http://dx.doi.org/10.1146/annurev. arplant.57.032905.105228

4. Meng Q, Goldberg ID, Rosen EM, Fan S. Inhibitory effects of Indole-3-carbinol on invasion and migration in human breast cancer cells. Breast Cancer Res Treat 2000; 63:147-52; PMID:11097090; http://dx.doi.org/ 10.1023/A: 1006495824158

5. Meng Q, Qi M, Chen DZ, Yuan R, Goldberg ID, Rosen EM, Auborn K, Fan S. Suppression of breast cancer invasion and migration by indole-3-carbinol: associated with up-regulation of BRCA1 and E-cadherin/catenin complexes. J Mol Med 2000; 78:15565; PMID:10868478; http://dx.doi.org/10.1007/ s001090000088

6. Firestone GL, Bjeldanes LF. Indole-3-carbinol and 3$3^{\prime}$-diindolylmethane antiproliferative signaling pathways control cell-cycle gene transcription in human breast cancer cells by regulating promoter-Sp1 transcription factor interactions. J Nutr 2003; 133 (7Suppl):2448S-55S; PMID:12840223
7. Sarkar $\mathrm{FH}, \mathrm{Li}$ Y Indole-3-carbinol and prostate cancer. J Nutr 2004; 134(12 Suppl):3493S-8S; PMID:15570059

8. Fan S, Meng Q, Auborn K, Carter T, Rosen EM. BRCA1 and BRCA2 as molecular targets for phytochemicals indole-3-carbinol and genistein in breast and prostate cancer cells. Br J Cancer 2006; 94:407-26; PMID:6434996

9. Kim JH, Jander G. Myzus persicae (green peach aphid) feeding on Arabidopsis induces the formation of a deterrent indole glucosinolate. Plant J 2007; 49:1008 19; PMID:17257166; http://dx.doi.org/10.1111/ j.1365-313X.2006.03019.x

10. Katz E, Nisani S, Yadav BS, Woldemariam MG, Shai B, Obolski U, Ehrlich M, Shani E, Jander G, Chamovitz DA. The glucosinolate breakdown product indole3 -carbinol acts as an auxin antagonist in roots of Arabidopsis thaliana. Plant J 2015; 82:547-55; PMID:25758811; http://dx.doi.org/10.1111/tpj.12824

11. Gray WM., Kepinski S, Rouse D, Leyser O, Estelle M. Auxin regulates SCF(TIR1)-dependent degradation of AUX/IAA proteins. Nature 2001; 414:2716; PMID:11713520; http://dx.doi.org/10.1038/ 35104500

12. Dharmasiri N, Dharmasiri S, Estelle M. The F-box protein TIR1 is an auxin receptor. Nature 2005 435:441-5; PMID:15917797; http://dx.doi.org/ $10.1038 /$ nature 03543

13. Kepinski S, Leyser O. The Arabidopsis F-box protein TIR1 is an auxin receptor. Nature 2005 435:446-51; PMID:15917798; http://dx.doi.org/ 10.1038 /nature 03542

14. Villalobos C, Caballero E, Sanz-Blasco S, Núñez L. Study of neurotoxic intracellular calcium signalling triggered by amyloids. Methods Mol Biol 2012; 849:289 302; PMID:22528098; http://dx.doi.org/10.1007/9781-61779-551-0_20
15. Grieneisen VA, Xu J, Marée AF, Hogeweg P, Scheres B. Auxin transport is sufficient to generate a maximum and gradient guiding root growth. Nature 2007; 449:1008-13; PMID:17960234; http://dx.doi.org/ 10.1038/nature06215

16. Friml J. Auxin transport - shaping the plant. Curr Opin Plant Biol 2003; 6:7-12; PMID:12495745; http://dx. doi.org/10.1016/S1369526602000031

17. Benkova E, Michniewicz M, Sauer M, Teichmann T, Seifertová D, Jürgens G, Friml J. Local, effluxdependent auxin gradients as a common module for plant organ formation. Cell 2003; 115:591-602; PMID:14651850; http://dx.doi.org/10.1016/S00928674(03)00924-3

18. Xu JBS. Dissection of Arabidopsis ADP-RIBOSYLATION FACTOR 1 function in epidermal cell polarity. Plant Cell 2005; 17:525-36; PMID:15659621; http:// dx.doi.org/10.1105/tpc.104.028449

19. Blilou I, Xu J, Wildwater M, Willemsen V, Paponov I, Friml J, Heidstra R, Aida M, Palme K, Scheres B. The PIN auxin efflux facilitator network controls growth and patterning in Arabidopsis roots. Nature 2005; 433:39-44; PMID:15635403; http://dx.doi.org/ 10.1038 /nature 03184

20. Sachs $T$. The control of patterned differentiation of vascular tissues. Adv Bot Res 1981; 9:151-262; http://dx. doi.org/10.1016/S0065-2296(08)60351-1

21. Sauer M, Balla J, Luschnig C, Wisniewska J, Reinöhl V, Friml J, Benková E. Canalization of auxin flow by Aux/ IAA-ARF-dependent feedback regulation of PIN polarity. Genes Dev 2006; 20:2902-11; PMID:17043314; http://dx.doi.org/10.1101/gad.390806

22. Zhou D, Zhou X, Ling Y, Zhang Z, Su Z. agriGO: a GO analysis toolkit for the agricultural community. Nucl Acids Res 2010; 38:W64-70; PMID:20435677; http://dx.doi.org/10.1093/nar/gkq310 